\title{
INSTITUTOS CONFÚCIO NOS PAÍSES DE LÍNGUA PORTUGUESA E SEU PAPEL NOS INTERCÂMBIOS POVO A POVO
}

\author{
QIAO Jianzhen 乔建珍 \\ Directora Chinesa do Confucius Classroom UFF/ \\ Universidade Normal de HEBEI, China
}

\begin{abstract}
Resumo: Como um dos membros importantes dos Institutos Confúcio (ICs) globais, os ICs nos países de língua portuguesa contribuíram muito para o intercâmbio entre a China e estes países nas áreas de educação, cultura, economia, diplomacia, etc. Este artigo começa com as informações básicas dos ICs globais, faz uma breve introdução de todos os ICs/CCs (Confucius Classroom) nos últimos catorze anos, tentando cobrir as influências dos ICs em diferentes partes de seu trabalho. No final, são dadas sugestões para o desenvolvimento futuro destes ICs/CCs para que os ICs/CCs contribuam mais para ajudar a melhorar a influência internacional da China e ajudar na construção de uma comunidade de futuro compartilhado para a humanidade.
\end{abstract}

Palavras-Chave: Instituto Confucius. Impacto. Intercâmbio Educacional. Intercâmbio Cultural.

Abstract: As one of the important members of the global Confucius Institutes (CIs), CIs in Portuguese-speaking countries have contributed greatly to the exchange between China and these countries in the areas of education, culture, economics, diplomacy, etc. This article starts with the basic information of global CIs, makes a brief introduction of all CIs / CCs (Confucius Classroom) in the last fourteen years, trying to cover the influences of CIs in different parts of their work. In the end, suggestions are made for the future development of these CIs / CCs so that the CIs / CCs do more to help improve China's international influence and help build a community of shared future for humanity.

Keyword: Confucius Institute, Impact, Educational Exchange, Cultural Exchange

\section{Introdução}

Com o desenvolvimento da economia chinesa, cada vez mais empresas chinesas saem para o exterior e a demanda pelo idioma chinês cresce globalmente, o número de Institutos Confucius vem aumentando e sua influência também tem aumentado gradualmente desde o establecimento do primeiro IC em Seul, Coréia do Sul, em 2004. "Até agora, 162 países (regiões) ao redor do mundo criaram 541 Institutos de Confúcio e 1, 170 Confucius 
Classroom". Os ICs não apenas oferecem cursos de língua e cultura chinesas, mas também promovem em grande parte o intercâmbio educacional, cultural, econômico e comercial entre a China e o resto do mundo, tornando-se uma importante plataforma de intercâmbio entre a China e o resto do mundo, desempenhando objetivamente um papel na promoção e integração cultural.

Distribuídos nos países de língua portuguesa nos quatro continentes na Europa, América, Ásia, África, os Institutos Confúcio também testemunham o desenvolvimento dos Institutos Confúcio em todo o mundo. Desde o IC na Universidade do Minho em Portugal, em dezembro de 2005, até a criação do IC de Medicina Tradicional Chinesa na Universidade Federal de Goiás no Brasil, em outubro de 2019, e o CC na Escola de Negócios do TimorLeste em 10 de dezembro, os ICs foram estabelecidos em oito países e regiões lusófonos nos recentes 14 anos. Existem 21 ICs e 6 CCs independentes que cobrem vários tipos de cooperação. Entre esses há ICs gerais estabelecidos em colaboração com universidades chinesas e estrangeiras, assim como dois ICs de Medicina Tradicional Chinesa (UC, Portugal, e UFG, Brasil) estabelecidos em colaboração com três universidades, também há IC na Universidade de Neto, Angola e IC independente na Universidade de Macau para ensinar chinês para estrangeiros em Macau. Os ICs nos países de língua portuguesa são muito diversos, com cursos que vão desde a escola primária até o mestrado em chinês como língua estrangeira, tanto acadêmicos como não acadêmicos, e as atividades dos ICs estão atraindo cada vez mais atenção. As atividades realizadas pelos ICs nos países de língua portuguesa também oferecem cada vez mais oportunidades de intercâmbio entre a China e estes países, e sua influência está em constante expansão.

Neste artigo, revisaremos a influência dos ICs/CCs nos países de língua portuguesa em termos de estabelecimento, status de ensino, atividades culturais, Summer Camp (Acampamentos de Verão), Chinese Bridge (Ponte Chinesa), bolsas de estudo, intercâmbio e cooperação acadêmica, e cobertura da mídia chinesa e estrangeira. 
Informações básicas sobre o estabelecimento dos ICs (CCs) nos países (região) de língua portuguesa

\begin{tabular}{|c|c|c|c|}
\hline País & Nome do IC/CC & Instituição Parceira da China & $\begin{array}{l}\text { Estabelecim } \\
\text { ento }\end{array}$ \\
\hline Angola & IC na Universidade de Neto & Universidade Normal de Ha'rbin & $2014 / 03 / 01$ \\
\hline \multirow{14}{*}{ Brasil } & $\begin{array}{l}\text { IC na Unesp (Universidade Estadual } \\
\text { Paulista) }\end{array}$ & Universidade de Hubei & $2008 / 07 / 24$ \\
\hline & $\begin{array}{c}\text { IC na UnB - Universidade de } \\
\text { Brasília }\end{array}$ & $\begin{array}{l}\text { Universidade de Estudos } \\
\text { Internacionais de Dalian }\end{array}$ & $2008 / 09 / 26$ \\
\hline & IC na PUC-Rio & Universidade Hebei & $2011 / 8 / 31$ \\
\hline & IC na FAAP, SP & $\begin{array}{l}\text { Universidade Internacional de } \\
\text { Negócios e Economia }\end{array}$ & $2012 / 07 / 19$ \\
\hline & $\begin{array}{c}\text { IC na UFRGS (Universidade de Rio } \\
\text { Grande do Sul) }\end{array}$ & $\begin{array}{l}\text { Universidade de Comunicação da } \\
\text { China }\end{array}$ & $2011 / 04 / 12$ \\
\hline & $\begin{array}{c}\text { IC na UFMG (Universidade Federal } \\
\text { de Minas Gerais) }\end{array}$ & $\begin{array}{l}\text { Universidade de Ciência e } \\
\text { Tecnologia de Huazhong }\end{array}$ & $2013 / 01 / 14$ \\
\hline & $\begin{array}{c}\text { IC na UPE (Universidade de } \\
\text { Pernambuco) }\end{array}$ & $\begin{array}{l}\text { Universidade Central de Finanças } \\
\text { e Economia }\end{array}$ & $2013 / 06 / 15$ \\
\hline & $\begin{array}{c}\text { IC na Unicamp (Universidade de } \\
\text { Campinas) }\end{array}$ & Universidade Jiaotong de Pequim & $2014 / 07 / 17$ \\
\hline & $\begin{array}{l}\text { IC na UEPA (Universidade Estadual } \\
\text { de Pará) }\end{array}$ & $\begin{array}{l}\text { Universidade Normal de } \\
\text { Shandong }\end{array}$ & 2014/07/17 \\
\hline & $\begin{array}{l}\text { IC na UFC (Universidade Federal de } \\
\text { Ceará) }\end{array}$ & Universidade de Nankai & 2014/7/17 \\
\hline & $\begin{array}{c}\text { IC na UFG (Universidade Federal } \\
\text { de Goiás ) }\end{array}$ & $\begin{array}{c}\text { Universidade Hebei de Medicina } \\
\text { Chinesa/ } \\
\text { Universidade de Estudos } \\
\text { Estrangeiros de Tianjin }\end{array}$ & $2019 / 10 / 15$ \\
\hline & $\begin{array}{l}\text { CC na UFF (Universidade Federal de } \\
\text { Fluminense) }\end{array}$ & \multirow{3}{*}{ Universidade Normal de Hebei } & \multirow{3}{*}{$2018 / 08 / 28$} \\
\hline & CC de Huaguang & & \\
\hline & CC de Nanmei Qiaobao & & \\
\hline Cabo Verde & IC na Universidade de Cabo Verde & & $2015 / 02 / 09$ \\
\hline Moçambique & $\begin{array}{l}\text { IC na Universidade Eduardo } \\
\text { Mondelane }\end{array}$ & Universidade Normal Zhejiang & $2011 / 04 / 22$ \\
\hline \multirow{7}{*}{ Portugal } & IC na Universidade de Minho & Universidade Nankai & $2005 / 12 / 09$ \\
\hline & IC na Universidade de Lisboa & $\begin{array}{l}\text { Universidade de Estudos } \\
\text { Estrangeiros de Tianjin }\end{array}$ & $2007 / 01 / 31$ \\
\hline & IC na Universidade de Coimbra & $\begin{array}{l}\text { Universidade de Estudos } \\
\text { Internacionais de Pequim }\end{array}$ & 2015/07/06 \\
\hline & IC na Universidade de Aveiro & $\begin{array}{l}\text { Universidade de Estudos } \\
\text { Estrangeiros de DALIAN }\end{array}$ & $2014 / 09 / 21$ \\
\hline & IC na Universidade de Porto & $\begin{array}{c}\text { Universidade de Estudos } \\
\text { Estrangeiros de Guangdong }\end{array}$ & $2018 / 12 / 05$ \\
\hline & CC no Colégio de São Bento & IC Universidade de Lisboa & $2014 / 7 / 21$ \\
\hline & CC no Colégio Internacional & Universidade de Minho & $2019 / 11 / 22$ \\
\hline $\begin{array}{l}\text { São Tomé e } \\
\text { Príncipe }\end{array}$ & $\begin{array}{l}\text { IC na Universidade de São Tomé e } \\
\text { Príncipe }\end{array}$ & Universidade de Hubei & $10 / 07 / 2019$ \\
\hline Timor Leste & $\begin{array}{l}\text { CC no Instituto Comercial de Timor- } \\
\text { Leste }\end{array}$ & Universidade de Shanxi & $2019 / 12 / 10$ \\
\hline $\begin{array}{c}\text { Região } \\
\text { Administrativ } \\
\text { a Especial de } \\
\text { Macau }\end{array}$ & IC na Univeridade de Macau & & $16 / 04 / 2018$ \\
\hline
\end{tabular}


Como berço da língua portuguesa, Portugal foi o primeiro país a criar os Institutos Confúcios, cujas atividades são mais abrangentes. ICs em Portugal são bem distribuídas e têm o maior impacto; atualmente existem cinco ICs e dois CCs. Além disso, assinaram-se um contrato entre o Ministério da Educação de Portugal e a Sede do Instituto de Confúcio da China para o ensino de chinês em 21 escolas secundárias. Os ICs em Portugal têm a mais alta distribuição populacional e a mais ampla gama de atividades de todos os países de língua portuguesa; foram criados nas três maiores cidades de Portugal e em várias das mais prestigiadas universidades; existem atualmente 5 ICs e 2 CCs. O Brasil, localizado no continente sul-americano com a maior população de países de língua portuguesa, tem 11 ICs e 3 CCs independentes; e o IC de Medicina Tradicional Chinesa na UFG, cuja criação foi testemunhada durante a visita do Presidente brasileiro à China em outubro de 2019, e este é também um exemplo de cooperação entre as províncias e estados da China e do Brasil;. O primeiro CC independente em uma universidade brasileira foi inaugurada na UFF em 28 de novembro de 2018. O IC na Universidade de Neto de Angola é um IC investido pelo Grupo CITIC da China, refletindo o entusiasmo das empresas chinesas em participar da construção dos ICs após a ida ao exterior e as atratividades dos ICs tornam-se cada vez mais atraentes para as empresas. O IC na Universidade de Mondlane em Moçambique, é o IC mais avançado e de mais rápido crescimento nos países africanos de língua oficial portuguesa. O IC na Universidade de Macau é um dos poucos ICs que não tem uma instituição parceira. A criação do Confucius Classroom na Escola de Negócios do Timor-Leste em dezembro de 2019 também acrescenta um caráter diferente às instituições anfitriãs da Confucius Classroom nos países de língua portuguesa e é o mais novo membro da família dos ICs/CCs nos países de língua portuguesa.

O IC tem como objetivo fornecer recursos e serviços de ensino de língua e cultura chinesa para países de todo o mundo, para atender plenamente às necessidades dos estudantes de língua chinesa no exterior e para contribuir para o desenvolvimento de um mundo multicultural e harmonioso. As principais atividades do IC incluem o ensino da língua e cultura chinesa, intercâmbios culturais, educacionais e esportivos sino- 
brasileiros, organização de testes orais e escritos de proficiência chinesa, treinamento de professores, incentivo e organização de estudantes, professores e pesquisadores brasileiros para estudar história chinesa, tradições chinesas e cultura contemporânea, literatura, relações sinobrasileiras, história dos imigrantes chineses no Brasil e organização de seminários acadêmicos, exposições de fotos e outras formas de atividades culturais. Nos últimos 14 anos, os ICs/CCs tornam-se um centro de idiomas, educação e intercâmbio cultural entre a China e os países de língua portuguesa, um centro de testes de língua chinesa, um centro de treinamento para professores de língua chinesa e uma importante plataforma e belo cartão de visita para o intercâmbio interpessoal entre a China e o Brasil.

\section{Diversificação de cursos - ampla cobertura e múltiplos níveis}

A principal missão dos ICs/CCs é divulgar a língua e a cultura chinesa, e o ensino da língua chinesa é a base de sua vida. Os ICs/CCs nos países de língua portuguesa se esforçam para implementar uma estratégia de "localização" e têm oferecido uma série de cursos de língua e cultura chinesa com a premissa de entender o sistema educacional local e respeitar a cultura e as leis locais. Como o IC opera com base na cooperação entre universidades chinesas e estrangeiras, todos os seus cursos são baseados nas universidades onde estão localizados e são oferecidos a crédito ou como cursos eletivos de acordo com as exigências do instituto, bem como uma variedade de cursos pagos ou gratuitos para servir às comunidades nas quais estão localizados.

Como primeiro IC nos países de língua portuguesa, o IC na Universidade do Minho se esforça para se adaptar às necessidades locais, oferecendo cursos desde a escola primária até o nível de mestrado, e em 2019 também estabeleceu CC na Escola Internacional do Porto, que oferece instrução padronizada em chinês para estudantes internacionais em Portugal.

Como o primeiro no Brasil, o IC Unesp estendeu seus cursos para 13 cidades do estado de São Paulo e também criou cursos de chinês em duas outras universidades federais, facilitando muito o forte desejo dos professores, estudantes e pessoas locais de aprender chinês. O IC na Universidade de Brasília oferece cursos de língua chinesa no Instituto Rio Branco do Ministério 
das Relações Exteriores do Brasil, o berço da formação diplomática brasileira. O IC na PUC-Rio dedica-se ao serviço dos estudantes e professores da instituição, oferecendo agora "Língua e Cultura Chinesa" I-VI para estudantes de graduação e pós-graduação, e "Introdução à Cultura Chinesa", o único curso neste tipo nos ICs que é ministrado em português. Todos os cursos entraram no sistema de crédito de suas universidades e se tornaram cursos eletivos. O IC na Universidade de São Tomé e Príncipe, que foi inaugurado há pouco tempo, também incorporou aulas de chinês ao currículo da universidade.

Atualmente, além dos cursos de língua chinesa em todos os níveis, os ICs nos países de língua portuguesa oferecem uma ampla gama de cursos culturais e palestras sobre temas como história e geografia chinesa, filosofia, religião, imigração, medicina tradicional chinesa, cinema, gastronomia, artes marciais, trajes, notícias, etc., que são muito necessários para a população local. Além das aulas culturais normais, oferecemos também cursos de esportes como tênis de mesa, badminton e shuttlecock, assim como hulusi, corte de papel e caligrafia chinesa e cursos de pintura de acordo com as características de cada país, que são muito populares entre os estudantes.

Além do trabalho nas suas universidades, os ICs também estão cooperando ativamente com os governos locais para integrar-se os cursos ao sistema de educação local. Desde 2013, o IC no Rio vem ajudando a Universidade Normal de Hebei e o governo estadual do Rio a assinarem um acordo de cooperação para integrar o curso de "Língua e Cultura Chinesa" no sistema educacional estadual do Rio. Recebeu notas altas na avaliação do MEC de 2017 e 2018 e agora se tornou uma escola de prestígio.

Os ICs pretendem se estabelecer na universidade onde está localizado, irradiando para os estados e províncias circunvizinhas, universidades e várias escolas primárias e secundárias. IC na UEPA no Brasil atendeu às preferências locais ao incorporar as artes marciais e o taiji ao currículo do IC, criando seu próprio currículo distinto. O IC na Universidade de Mondlane em Moçambique irradiou os cursos de seus próprios locais de ensino para escolas e universidades em todo o país; o IC no Cabo Verde cooperou com instituições educacionais locais e o IC PUC-Rio está trabalhando com os governos estaduais e municipais locais, universidades e empresas chinesas no Brasil para levar cursos de língua e cultura chinesa a 
essas instituições, que estão ansiosas para ter um contato próximo com a língua e cultura chinesa, proporcionando-lhes uma plataforma para aprender chinês e entender a China, e expandindo a influência da língua e cultura chinesa na região.

Os dois únicos ICs de Medicina Tradicional Chinesa nos países de língua portuguesa também administram seus próprios programas. O IC UC oferece cursos eletivos de medicina chinesa para estudantes da faculdade de medicina da universidade, enquanto o IC de Medicina Chinesa na UFG no Brasil oferece cursos de acupuntura, tui na e massagem para a escola de enfermagem, bem como um curso chinês de medicina chinesa. Isto lançou as bases para a verdadeira introdução da MTC no sistema de saúde brasileiro. A abertura de cursos de língua chinesa em diferentes universidades no Brasil também lançou as bases para a entrada da língua chinesa no programa "Idiomas sem Fronteiras" do MEC do Brasil.

Os ICs nos países de língua portuguesa estão ativamente envolvidos na cooperação horizontal com diferentes faculdades das universidades anfitriãs, com outras universidades do país e com universidades nacionais, no ensino, atividades culturais e pesquisa científica; em cooperação com os governos locais no ensino da "língua chinesa"; em cooperação com empresas chinesas do país para ensinar a língua chinesa com características especiais, a fim de treinar e selecionar funcionários estrangeiros adequados para as empresas.

Com a crescente influência da língua chinesa, os cursos dos ICs estão recebendo cada vez mais atenção de todos os países. Não é de se admirar que em maio de 2013, durante sua visita à China, o presidente português Silva disse que a língua chinesa está se tornando cada vez mais importante no mundo.

\section{Diversidade de atividades culturais}

Língua e cultura são partes inseparáveis de um todo, e as atividades culturais baseadas na plataforma dos cursos de língua chinesa são uma das principais atividades dos ICs nos países de língua portuguesa, e a variedade de atividades culturais chinesas reflete a atratividade da cultura chinesa para a 
população local. Os ICs/CCs nestes países se estabeleceram ativamente na área local e realizaram uma ampla gama de atividades culturais.

No ano de 2019, o IC UC sediou a celebração do Dia Mundial da Medicina Chinesa e a cerimônia de lançamento da turnê TCM Portugal. Escolas, associações e especialistas de MTC de Portugal se reuniram para celebrar este evento. O IC na Universidade do Minho, Portugal, realizou uma exposição de pinturas chinesas com o tema "Tinta e lavagem que duram mil anos, cores que atravessam a Rota da Seda", e dois workshops sobre caligrafia chinesa e pintura para professores e estudantes da Faculdade de Arquitetura. O passeio "Vento Chinês - Kung Fu" despertou o interesse do povo português pelas artes marciais e pela cultura chinesa e foi bem recebido, promovendo o intercâmbio cultural entre a China e Portugal. Através do IC, cada vez mais portugueses puderam conhecer a China, e através de sua participação eles foram inspirados a aprender a língua chinesa e a entender a China. O IC Universidade de Aveiro ajudou a organizar a 14a Bienal Internacional de Arte e Cerâmica de Aveiro, que proporcionou um banquete para que a população local desfrutasse da cerâmica chinesa.

No Brasil, o IC Unesp realizou o "Terceiro Concerto de Percussão Chinesa e Celebração do Dia Nacional" e o Festival das Lanternas de São Paulo. Em colaboração coma Prefeitura de São Paulo, o Instituto Cultural da Cidade de São Paulo e o Centro Cultural da Cidade de São Paulo organizaram conjuntamente a Quinta "Mostra de Cinema Chinês de São Paulo".

O IC Unicamp organizou "Dia Nacional do Chá" para fazer o povo brasileiro entender a bebida nacional chinesa, e o povo chinês e brasileiro lembram juntos a história dos imigrantes chineses no Brasil por mais de 200 anos, e a história do cultivo do chá no Brasil. Em 2019, o IC PUC-Rio organizou a exposição "Guizhou Intangible Cultural Heritage in Rio", onde figurinos coloridos de Guizhou e desenhos chineses fizeram o público brasileiro sentir pela primeira vez a perfeita combinação de figurinos chineses tradicionais e modernos, e foram cativados por eles.

Além dos grandes eventos culturais que são organizados por iniciativa própria ou em cooperação com outras instituições, muitos ICs também estão fazendo uso das plataformas existentes em suas universidades ou na região para atender à demanda local pela cultura chinesa. Atividades 
como mini-cursos sobre a língua chinesa, caligrafia chinesa, pintura chinesa, etc., tornaram o povo dos países de língua portuguesa cada vez mais interessado na China e em sua língua e cultura, mais interessado em aprender mais sobre o passado e o presente da China, e ansioso por mais cooperação entre o país anfitrião e a China, a fim de alcançar uma situação vantajosa para ambas as partes e uma verdadeira comunidade do destino humano.

\section{Programa de Intercâmbio Educacional do IC}

A amizade entre as nações está na proximidade do povo, e a proximidade do povo está no coração. Os ICs desempenham um papel fundamental nos intercâmbios educacionais entre a China e os países de língua portuguesa, e a variedade de programas de intercâmbio educacional é também uma parte importante desses intercâmbios. Os ICs/CCs dos países de língua portuguesa organizam visitas à China por grupos de estudantes, professores e educadores de diferentes níveis, a fim de dar-lhes uma melhor compreensão da China moderna e de seu sistema educacional, e para melhor desempenhar um papel maior no intercâmbio educacional.

\section{Summer Camp}

Desde 2013, o IC PUC-Rio tem organizado seis "Summer Camp" consecutivos, no qual quase 100 estudantes de 6 universidades em 6 cidades de 3 estados brasileiros vieram à China para um curso curto de língua chinesa de 2-3 semanas e uma experiência cultural chinesa.

Em 2019, pelo quarto ano consecutivo, o IC PUC-Rio organiza um Summer Camp de Futebol pelos alunos e professores do CEMJGS Intercultural Brasil-China visitarem a China para a "Integração de Pequim-Tianjin-Hebei e Novo Xiongan". 108 alunos e professores deste colégio de ensino médio do Rio de Janeiro vieram para a China nos últimos quatro anos. Em apenas 3 semanas por ano, eles visitaram 3 ou 4 cidades, jogaram 6-8 partidas amistosas, visitaram 4-6 museus, visitaram 4-6 escolas e universidades, o Sede Geral do IC, visitaram a Grande Muralha, a Cidade Proibida, o Ninho de Pássaros, experimentaram a rica atmosfera do Festival Chinês de Meio do Outono e tiveram interações culturais com estudantes universitários e de ensino médio. 
Os participantes brasileiros ganharam uma boa compreensão da China moderna e da escala do início do futebol escolar na China, e agora estão ansiosos para sua próxima visita à China, ou mesmo para estudar em uma universidade na China, para realizar ainda mais seus próprios sonhos com a China. A visita à China certamente será um grande impulso para a melhoria do nível do futebol escolar na China, o desenvolvimento do intercâmbio de educação futebolística entre a China e o Brasil, e a mudança no nível de educação futebolística no Brasil. Cerca de 3.000 estudantes e professores chineses e brasileiros participaram do evento em 2019, causando uma grande agitação em todos os lugares por onde passaram.

Além dos "Summer Camp", organizamos Missão à China pelos funcionários e educadores brasileiros. Em outubro de 2013, organizamos a primeira delegação de educadores brasileiros na China, liderada pelo Secretario de SEEDUC RJ com um total de 11 pessoas. A missão foi um grande impulso para o futuro estabelecimento da Colélgio Intercultural Brasil-China. Outros ICs nos países de língua portuguesa também organizaram Summer Camp para visitar a China. O programa "Summer Camp" tornou-se uma das principais maneiras para os estudantes e professores aprenderem sobre a China de hoje com seus próprios olhos.

\section{Missão dos Educadores}

O desenvolvimento dos ICs afeta não somente os estudantes e professores e o público, mas também os reitores de universidades, diretores das escolas primárias e secundárias e autoridades educacionais de todos os níveis que estão encarregados da educação, que têm vontade de integrar o ensino da língua chinesa no sistema educativa local e também para trocar e cooperar com a China na educação e, portanto, precisam aprender sobre a China, especialmente sobre seu sistema educacional e como ele funciona. Por esta razão, os ICs nos países de língua portuguesa organizaram grupos de educadores em diferentes níveis e em diferentes números para tentar atender suas necessidades a fim de promover ainda mais a localização e o desenvolvimento sustentável do ensino e das atividades culturais 
O IC PUC-Rio e o Grupo Coimbra de Universidades Brasileiras organizaram conjuntamente a primeira delegação de reitores de universidades brasileiras à China, incluindo 15 reitores, vice-reitores e diretores de departamentos internacionais de 12 universidades brasileiras. Eles visitaram quase 10 universidades na China, assinaram 6 acordos de cooperação, visitaram museus, bibliotecas, exposições de pintura Chinesa, locais históricos como Cidade Proibida, Grande Muralha, etc., China Scholarship Council, a Academia Chinesa de Ciências Sociais, a Embaixada do Brasil, etc., e foram recebidos pelo Embaixador do Brasil na China.

O sucesso desta missão também ajuda a promover o reconhecimento mútuo precoce das qualificações acadêmicas entre a China e o Brasil, estabelecendo uma boa base para mais intercâmbios educacionais entre os dois países.

\section{Chinese Bridge (Ponte Chinesa) - Concurso de Língua Chinesa para Estudantes Universitários e do Ensino Médio}

"A "Ponte Chinesa" é uma competição internacional de língua chinesa organizada pela sede do Instituto Confucius, e é uma marca conhecida no campo do intercâmbio cultural em todo o mundo. A competição é dividida em 3 grupos: "Ponte Chinesa" para alunos do ensino médio, para os alunos universitários e para os alunos estrangeiros na China. A competição é realizada uma vez por ano e é organizada e implementada pelo comitê organizador do Concurso "Ponte Chinesa".

O concurso chinês visa despertar o entusiasmo de jovens estudantes de todo o mundo para aprender chinês e melhorar a compreensão mundial da língua e da cultura chinesas. Atualmente, a competição se tornou uma importante plataforma para estudantes de todo o mundo aprenderem chinês e entenderem a China, e construiu uma ponte entre a China e os jovens de todo o mundo.

Desde sua criação, os ICs nos países de língua portuguesa têm participado ativamente do concurso "Ponte Chinesa". Em 2007, foi realizada a primeira competição da ponte chinesa em Lisboa, capital de Portugal, que iniciou a competição da ponte chinesa nos países de língua portuguesa. No 
Brasil, o primeiro concurso "Ponte Chinesa" para estudantes universitários foi realizado desde 2012. Em Moçambique, a primeira competição para estudantes universitários começou em 2016.

Em 2014, Mônica, uma estudante brasileira, ganhou o campeonato mundial de "Ponte Chinesa", que foi a primeira vez que uma aluna de um país de língua portuguesa ganhou este prêmio.

Relativamente o ensino de lingua e cultura chinesa começou mais tarde e a Ponte Chinesa é um evento relativamente novo no mundo de língua portuguesa. O concurso para alunos do ensino médio no Brasil começou em agosto de 2015 e tem organizado para 5 edições até 2019. Um total de 18 estudantes brasileiros do ensino médio e 6 professores realizaram seu sonho de ir para a China através da competição, e alguns deles desde então começaram realizar o sonho de estudar na China, o que é inédito na história da educação brasileira.

Atualmente, o número de alunos que estudam a lingua e cultura chinesas nos países de língua portuguesa já ultrapassou 20.000. O sucesso da "Ponte Chinesa" não só despertou o entusiasmo dos estudantes para aprender chinês, mas também promoveu muito o intercâmbio educacional e cultural entre a China e os países de língua portuguesa, criando uma boa plataforma para as empresas chinesas saírem e para os intercâmbios estrangeiros da China. Muitos estudantes da "Ponte Chinesa" optaram por continuar seus estudos da língua chinesa, prosseguir seus estudos ou usar suas habilidades linguísticas para trabalhar em empresas chinesas ou organizações locais em seus países anfitriões, ou tornar-se professores locais após a graduação e permanecer no ICs para treinar outros. Eles também se tornaram uma grande força na promoção do programa nos países de língua portuguesa.

\section{Programa de bolsas de estudo}

O aprendizado de idiomas é um processo duradouro e requer um bom ambiente de idiomas. Por esta razão, o programa de bolsas de estudo do IC tornou-se uma das principais maneiras para os estudantes estrangeiros melhorarem ainda mais o seu domínio da lingua chinesa, aprenderem sobre a China até tornarem-se sinólogos. Desde a criação do programa Bosla do IC 
(Confucius Institute Scholarship) em 2009, quase 50.000 estudantes de 166 países e regiões foram agraciados com bolsas de estudo pelos ICs. No ano 2019 as bolsas para os alunos de países de língua portuguesa incluem: quatro anos de graduação, dois anos de chinês de mestrado como língua estrangeira e quatro anos de doutorado e mais um ano letivo e um semestre.

Além disso, os ICs também estão ajudando a promover as bolsas pelo China Scholarship Council para ajudar estudantes de países de língua portuguesa a se candidatarem a um mestrado ou doutorado na China. Após a graduação, eles retornam ao trabalho no seu país ou permanecem na China, desempenhando também um papel indispensável no intercâmbio entre a China e os países portugueses.

A permanência do intercâmbio educacional reside na interação. Por isso, os ICs nos países de língua portuguesa também fizeram pleno uso de suas plataformas para promover programas de bolsas de estudo em seus países e para incentivar os estudantes chineses a estudar nestes países. Por exemplo, o IC PUC-Rio coopera com universidades e institutos de pesquisa locais para promover programas de bolsas de estudo no Brasil e trazer estudantes chineses para o Brasil para fazerem doutorado. Vários estudantes se formaram no programa, e mais de uma dezena de universidades e institutos de pesquisa brasileiros expressaram interesse em aceitar estudantes chineses. Vários ICs em Portugal também desempenham seu papel em trazer muitos estudantes chineses para estudar em Portugal.

\section{Organização ou participação em conferências acadêmicas internacionais}

Os ICs são também um componente importante da internacionalização de universidade onde localiza. O número e o nível de participação dos ICs nas atividades acadêmicas locais também é um indicador importante da internacionalização da universidade. Além do ensino da língua chinesa e das atividades culturais, é também importante que ICs/CCs estejam bem integradas nas atividades acadêmicas e de intercâmbio internacional da universidade. Ao longo dos anos, os ICs/CCs nos países de língua portuguesa também aproveitam suas próprias vantagens e organizam ou participam de 
várias conferências acadêmicas e de internacionalização universitária em suas universidades de acordo com as características de suas próprias universidades,

Em 2019, o IC na Universidade de Aveiro realizou o segundo simpósio internacional sobre "Diálogo Intercultural Portugal-China", e foi sede do "Instituto Confucius". Em 2019, o Instituto Confúcio da Universidade de Aveiro, em Portugal, realizou o segundo seminário internacional "Diálogo Intercultural Portugal-China" e sediou uma conferência de alguns ICs Europeus sobre o tema "Construindo um sistema de ensino chinês para os Institutos de Confúcio". 21 Institutos de Confúcio de 16 países europeus participaram da reunião, o que proporcionou discussões úteis para o estabelecimento de um sistema de ensino científico chinês sólido para os Institutos de Confúcio.

O IC PUC-Rio participou de um seminário de uma semana sobre o tema da China, organizou o $2^{\circ}$ Seminário Internacional sobre Migração Chinesa no Brasil, participou da Conferência de Grupo Coimbra de Universidades Brasileiras, desde 2013, do Encontro de Universidade Tordisilhas. A CC UFF organizou o "Simpósio Internacional sobre a China e o Mundo por volta da Segunda Guerra Mundial", que muito contribuiu para a visibilidade e influência da UFF e acrescentou à internacionalização da Universidade, que foi bem elogiado pelos participantes e pela UFF.

\section{Conclusão}

Os Institutos de Confúcio nos países lusófonos estão em funcionamento há mais de 14 anos, e se espalharam basicamente por todos os membros nos países e regiões de língua portuguesa. Há um número razoável de Institutos de Confúcio, tanto ICs como CCs, assim como os Institutos de Confúcio de Medicina Tradicional Chinesa e outros Institutos de Confúcio com características excepcionais.

Entretanto, o corpo docente dos Institutos Confucius nos países de língua portuguesa ainda não é muito estável. Os ICs/CCs não há professores locais suficientes e não há muitos materiais didáticos chineses localizados em português. Não há pesquisas suficientes sobre a situação nacional, e ainda não 
há muito alcance para as províncias e cidades. Muitos cursos dos Institutos de Confúcio ainda não estão integrados ao sistema de educação local, e também faltam de ensino e gestão localizados, etc. Estas são questões que precisam ser tratadas no futuro. Somente quando estiverem verdadeiramente localizados, os Institutos Confúcio e Confucius Classrooms poderão continuar a contar a história chinesa, aumentar a influência da China nos países de língua portuguesa e fazer mais esforços para construir uma comunidade de destino humano.

Recebido em 20 de novembro de 2020

Aceito em 15 de dezembro de 2020 